\title{
INFLUENCE OF CONSTRUCTIONAL \\ sciendo AND KINEMATIC PARAMETERS OF THE NEW SOLUTION OF ROADHEADER MINING HEAD ON THE EFFECTIVENESS OF ITS WORK
}

doi:10.2478/mape-2018-0014

Date of submission of the article to the Editor: 05/2018

Date of acceptance of the article by the Editor: 07/2018

MAPE 2018, volume 1, issue 1, pp. 101-108

PhD. Eng. Krzysztof Kotwica, AGH Prof.

AGH University of Science and Technology, Poland

MSc. Paweł Sienkiewicz

Ferrovial Agroman, London, United Kingdom

\begin{abstract}
The paper presents a new solution of a mining head for roadheader designed for hard and very hard rock mining. The mining head was equipped with mini disk tools with a complex trajectory. The results of field tests were presented, under which the effectiveness of the new mining head solution was observed. The load and vibrations of the mining head, dustiness and grain size of the excavated material as well as disk tool wear were measured. These tests were carried out for various constructional and material parameters of the used asymmetrical mini disk tools and kinematic parameters of the mining head.
\end{abstract}

Keywords: hard rock, mining, roadheader, tool wear, efficiency

\section{INTRODUCTION}

In underground mining industry most of the galleries or tunnels are drilled with mechanical methods - applying arm roadheaders. But mining hard and very hard rocks, using the current cutting tools and mining heads, is becoming less and less effective. It is related mainly to smallcutting advance rate and very high cutting tools wear of the roadheaders, so the cutting process became economically ineffective.

Therefore, the steps to develop new rock mining techniques have been undertaken. In the Department of Mining, Dressing and Transportation Machines, AGH University of Science and Technology in Krakow, new solutions of mining disk tools and mining heads were developed and successful investigation of rock mining techniques with use of these tools and mining heads has been performed. These mining tools and heads were designed especially for roadheaders. The construction solution of new innovative mining head, its working mode and results of performed laboratory and industrial researches are described below.

\section{INNOVATIVE SOLUTION OF MINING HEAD WITH DISK TOOLS}

Mining hard and very hard rock (especially the ones that contain silica or its compounds and derivatives in their chemical composition, or inclusions of effusive rocks) with application of methods based on cutting, causes a great deal of tools wear-related problems. Such rocks require high cutting forces. Mining process generate also the hazardous - sparking and dustiness. Especially during coal galleries face excavation in underground coal mines, ignition of methane is possible and gas explosion (Prostański, 2017).

The second most commonly applied method of compact rocks mechanical mining, is mining with static pressure, causing rock destruction by its crushing. It is realized by disk tools, usually symmetrical. Whereas, asymmetrical disk tools have been used as mining tools for longwall shearers to increase output of a large size grade. Conducted industrial tests 
demonstrated usefulness of such equipment for obtaining higher product graining. Asymmetrical disk tools are applied in the technique of mechanical mining not only as crushing devices but also in the undercutting method (Krauze et al., 2009; Bołoz, 2018).

The principle of the undercutting method is mining a rock by its cutting off towards a free space. A disk tool affects the rock tangentially to the surface of the mined body, similarly as for cutting tools, but the difference is that here it uses the disk rolling movement which efficiently eliminates sliding friction in favour of rolling friction. Figure 1 presents a diagram of mining with the undercutting method. Application of disk tools in that way lowers energy consumption and pressure forces. It allows designing mining machines with respectively lower energy demands, and lower requirements concerning stability than in case of machines equipped with classical crushing disks, operating perpendicularly towards the surface of a mined body (Weber, 1994).

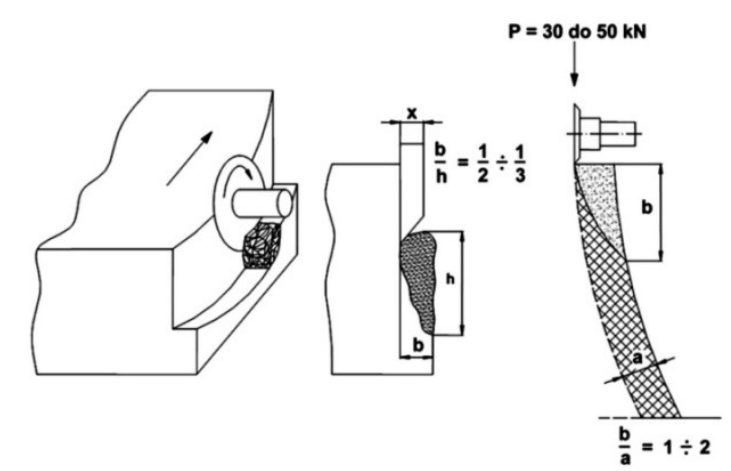

Fig. 1. Diagram of the undercutting method mining principle

Source: (Weber, 1994).

That is why the idea of the undercutting method was developed in order to design an innovative construction of mining head, equipped with mini asymmetrical disk tools. In proposed design motion of tools will be forced, and will cause mining of a rock body with tools along complex movement trajectory. It allows crossing of mining lines of individual disk tools, and facilitates mining compact rocks through breaking off rock furrows. It should lower energy consumption of the process (Gospodarczyk et al., 2013). Disk tools were mounted on separate plates that could rotate on the mining head body, and are propelled independently from it.

Estimating the parameter values for special solution of mining head design through theoretical simulation was very complicated or in some cases even impossible. That is why tests of compact rock mining with disk tools on a specially constructed lab stand were suggested. The results of these laboratory research allowed to choose the values of basic parameters for new solution of mining head and developed prototype of this head (Mendyka, 2017).

The works were performed in cooperation with the REMAG Company - the Polish producer of roadheaders. It was planned to work out and adapt the new head solution for a medium type roadheader KR150. On the basis of an analysis of milling heads used on this roadheader, it was assumed that length of the new solution should not exceed $1750 \mathrm{~mm}$, its diameter $859 \mathrm{~mm}$ and weight 5 tones. The proposed model of the head comprised mounting three plates with eight disk tools on its body. The body head will have an ability of independent rotation in relation to plates with disk tools. A preliminary model and view of the new head solution are presented in Figure 2 (Gospodarczyk at al., 2010, 2013). During its development, it was additionally assumed that the drive of the plates with disc tools will be realized by an electric engine of $150 \mathrm{~kW}$ power mounted on the roadheader arm, whereas the drive of the head body will be realized by two hydraulic engines HS 0.8. Following the presented model, the head consists of a body (1) propelled through a cylindrical gear of external meshing (6) by two hydraulic engines HS 0.8 (7). There is a 
two-stage toothed gear (4), with the first stage of cylindrical type and the second of conical one. The gear is propelled through a central shaft (5) directly connected to the $150 \mathrm{~kW}$ electric engine. The gear (4) transmits the drive to the three plates with disk tools (2). Asymmetrical disk tools are mounted on the plates (3).

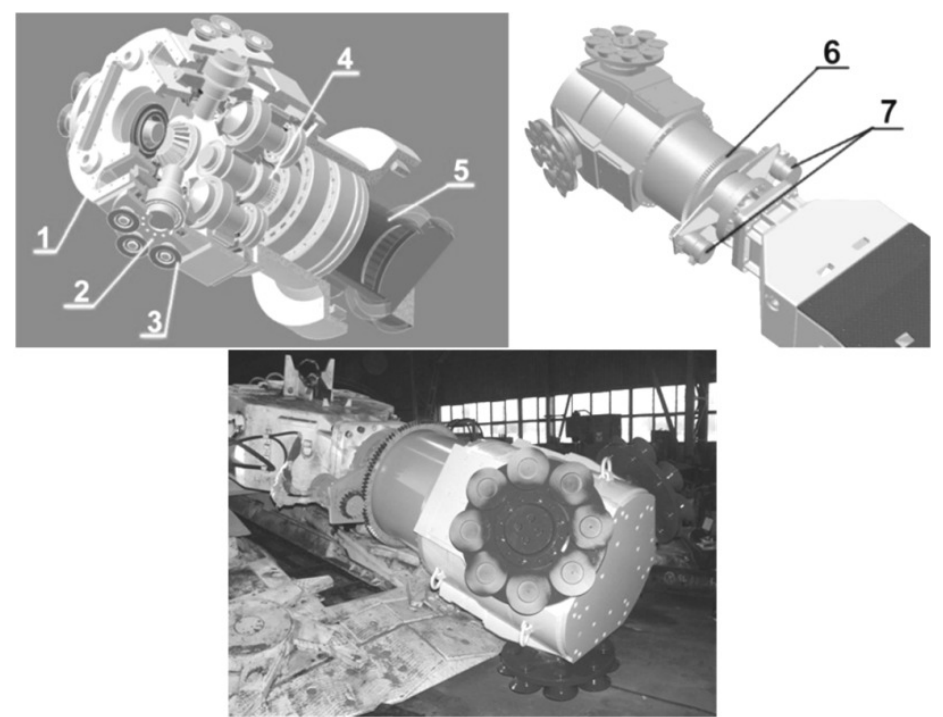

Fig. 2. A preliminary model and view of a mining head with asymmetrical disk tools of complex motion trajectory

Source: (Gospodarczyk et al., 2010).

\section{RESULTS OF FIELD TESTS WITH NEW MINING HEAD}

The preliminary tests were performed on artificial large size concrete block of uniaxial compressive strength of about 40 up to $80 \mathrm{MPa}$ prepared at REMAG Company. During the initial tests, a change of the head body rotations was planned within the range - from 10 to $30 \mathrm{rpm}$, and for the plates with disk tools - from 20 to $200 \mathrm{rpm}$. Mining effectiveness, load, vibrations and the level of the tools wear were measured as well as granulation of the obtained output (Gospodarczyk et al., 2013).

The test were started with the head body rotations at counter clockwise direction, and rotations of plates with disc tools at clockwise direction. Disk tools were mounted on the plates with the flat side out. The new head solution worked with assumed parameters without any serious issues. At lower values of rotations, very large output graining was obtained. Moreover, it was accompanied by high vibrations of the head.

An increase of rotational speed of the plates with disc tools caused lowering the vibrations, but it increased dust production. Additionally, with the maximum rotational speed sparking occurred at the contact of the tools with the rock. The best effects of the work - large graining of the output, low engines load, and limited vibrations were obtained for the head body rotations of app. $20 \mathrm{rpm}$, and the plates rotations value of app. $60 \mathrm{rpm}$. The change of direction of the head body or plates with disk tools rotation onto the opposite had a highly negative influence on the engines load and disk tools, and the plates wear (Gospodarczyk et al., 2013). View of the obtained output and a typical mined surface of the block for correct and incorrect working conditions is shown in Figures 3 and 4. 


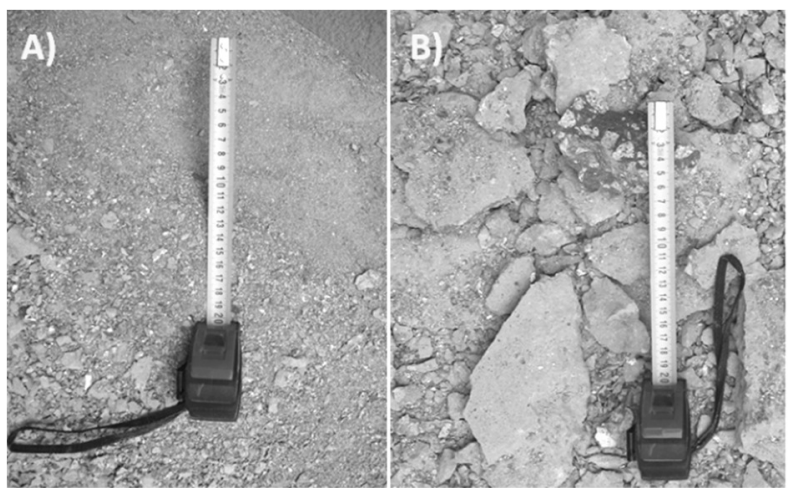

Fig. 3. A view of the obtained output during mining: A) with incorrect work conditions, B) with correct work conditions

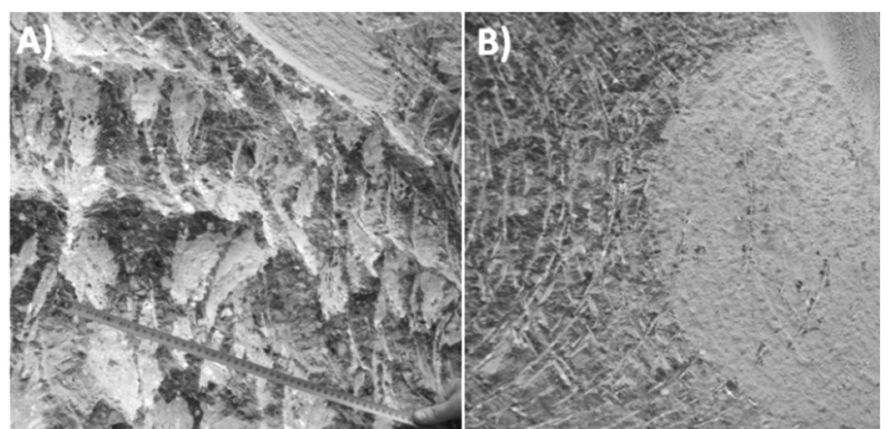

Fig. 4. A view of the obtained concrete block surface after mining: A) with correct work conditions, B) with incorrect work conditions

No considerable symptoms of the disk tools wear were noticed. The change of direction of the head body or plates with disk tools rotation onto the opposite had a highly negative influence on the engines load and disk tools, and the plates wear. To increase the life period and decrease the wear of the flat plates with disk tools, there were changed by another one. Instead of a round plate a plate in the shape of flower petals was suggested. The disk tools were mounted on the new plates so that their axis of rotation was tilted inwards by an angle of $-5^{\circ}$ (Gospodarczyk et al., 2011). The old plate version with traces of wear and new plate with disk tools is shown in Figure 5. In order to check the influence of mounting and the deflection angle of the rotational axis of the disk tool, new exchangeable holders of these tools were made which allow disk tools mounting at an angle of $-5^{\circ}, 45^{\circ}$ and $90^{\circ}$ relative to the surface of the plate. The models of these holders are shown in Figure 6 and the view of the plates with disk tools with these holders during field tests are shown in Figure 7.

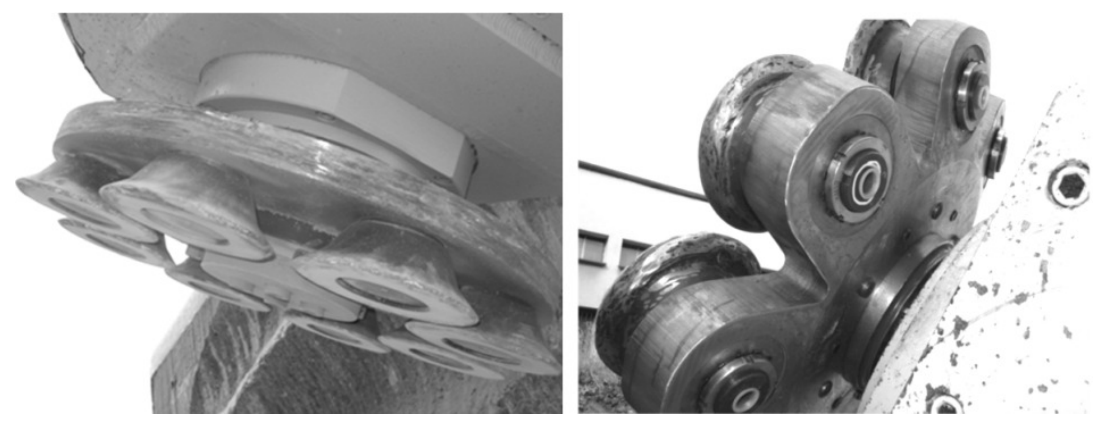

Fig. 5. A view of flat and round plate with traces of wear (left) and new plate in the shape of flower petals (right) (Gospodarczyk et al., 2011) 
a)

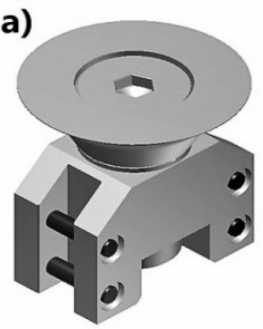

b)

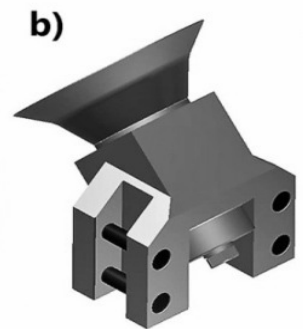

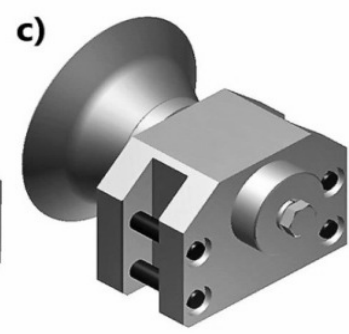

Fig. 6. Models of new exchangeable holders of disk tools allowing mounting them at an angle of: a) $90^{\circ}$, b) $45^{\circ}$ and c) $-5^{\circ}$ relative to the surface of the plate

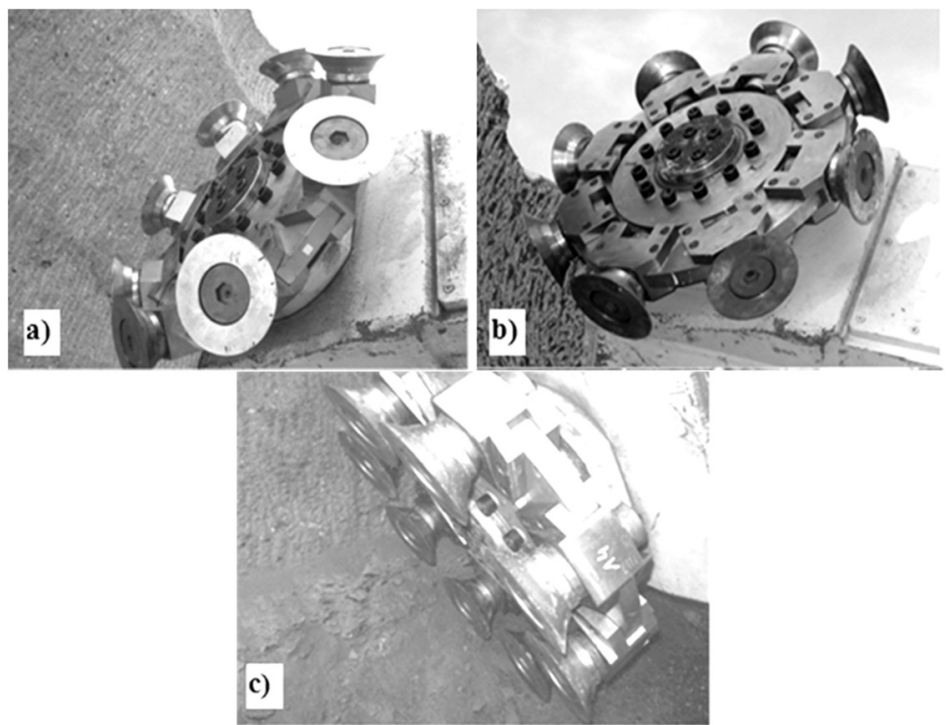

Fig. 7. A view of the plates with disk tools mounted in the holders at an angle of: a) $45^{\circ}$, b) $90^{\circ}$ and c) $-5^{\circ}$ relative to the surface of the plate

The attempts to excavate the block with disk tools mounted at $45^{\circ}$ and $90^{\circ}$ to the surface of the plate surface ended with a quick and catastrophic wear of the tool. The view of the destroyed tool mounted at an angle of $90^{\circ}$, compared to the tool fixed at an angle of $-5^{\circ}$ after about an hour of work, is shown in Figure 8. The attempts to replace a disk tool with a smooth wedge by another, reinforced with sintered carbide inserts, have been also unsuccessful. The inserts were broken after few minutes of the work (Gospodarczyk et al., 2011). The view of the new solution of disc tools reinforced with sintered carbide inserts and view of traces of carbide inserts breakage is shown in Figure 9.

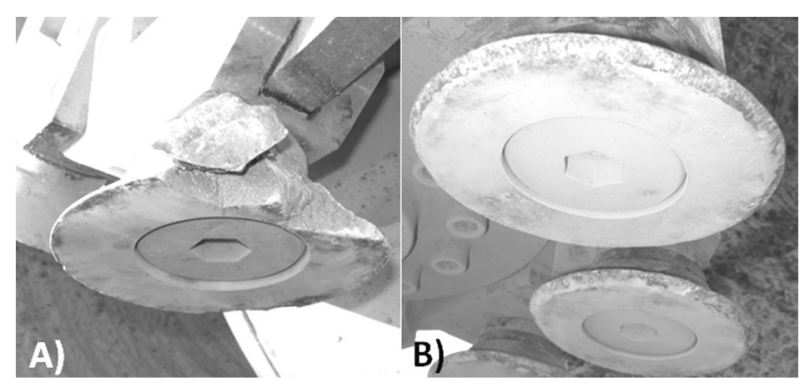

Fig. 8. View of the disk tool wear: A) disk tool mounted at an angle of $90^{\circ}, \mathrm{B}$ ) disk tool mounted at an angle of $-5^{\circ}$ 


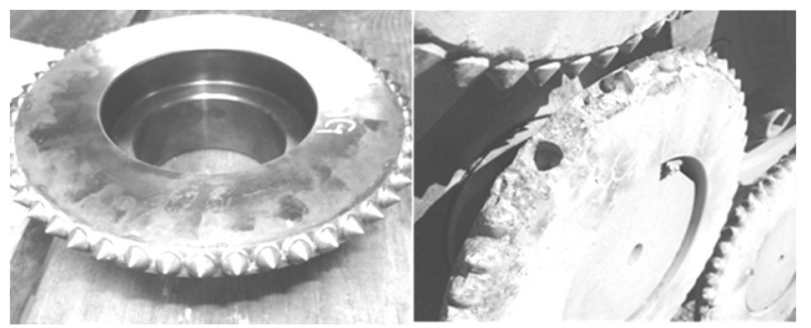

Fig. 9.View of disc tool reinforced with sintered carbide inserts and traces of carbide inserts breakage

Source: (Gospodarczyk et al., 2011).

During the last phase of the field tests, the mining head was mounted on a larger roadheader FR250 - manufactured by FAMUR company, with more weight - over 65 tones and equipped with a larger power electric motor $-250 \mathrm{~kW}$. Two additional hydraulic motors HS 0.8 to drive the mining head body were also included. This allowed for better, more stable operation of the mining head and the possibility of mining at greater depths. The view of this roadheader and mining head before and during the trials is shown in Figure 10.

During the tests, using disk tools made of different materials and by various methods, the efficiency of mining was checked. Disk tools had the same diameter $-170 \mathrm{~mm}$ and wedge angle of $45^{\circ}$. They were made of tool steel, Hadfield or low-alloyed (GS42CrMo4) cast steel and ADI spheroidal cast iron. The tools manufactured from tool steel type NZ3 were fullhardened, to a hardness of over $55 \mathrm{HRC}$. The tools manufactured from tool steel type $36 \mathrm{HNM}$ were surface- hardened and tempered. Tools made of cast steel and cast iron were machined after casting. After this mechanical treatment, it was noticed that especially tools made of cast steel had numerous castings defects - blisters and pores. These tools have been disqualified. These are shown in Figure 11.

During concrete block mining with larger cutting depth, the best results were obtained for tools made from tool steel type $36 \mathrm{HNM}$. After one hour operation there were not significant traces of wear observed. In the case of disk tolls made from tool steel NZ3, already after very short work numerous edge breaks as well as cracking and breakage of the part of tools were noticed.

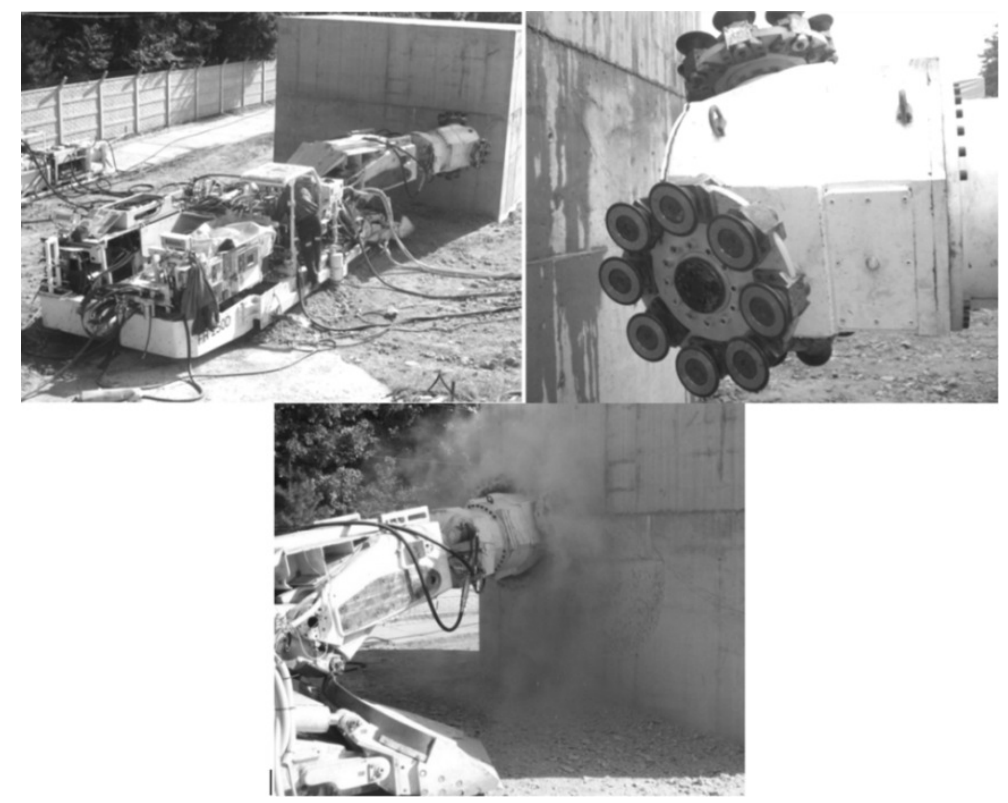

Fig. 10. A view of FR250 roadheader with new mining head with disk tools before and during the field tests 


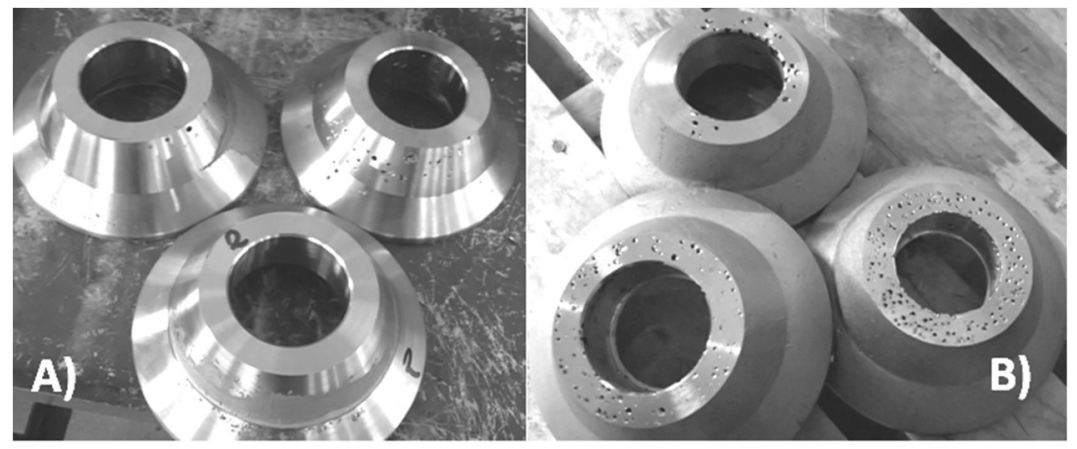

Fig. 11.A view of defective copies of disc tools made of cast steel

However, in the case of disk tools made of ADI cast iron, no breakage of the tool edge but its systematic abrasive wear was observed. The outside diameter of cast iron tools after about 30 minutes of work was decreased an to value of about $135-140 \mathrm{~mm}$. This diameter value did not allow further work. The wear view of tools made from tool steel NZ3 and ADI type cast iron is shown in Figure 12. The reason of quick tools wear was probably to large cutting depth and movement speed of mining head. Combination of both of these parameters caused a heavy load on the tools.

\section{CONCLUSION}

The suggested solution of mining head with asymmetrical disk tools of complex motion trajectory proved its usefulness while compact rocks mining, and can be used as an alternative for existing mining heads of roadheaders. A selection of proper configuration of direction and number of rotations of the head body and plates with disk tools is necessary to obtain the most favourable parameters of the mining operation - high output graining, low load of drive engines and low vibration levels.

It is also necessary to develop and implement a solution of abrasion and impact load resistant disk tools, as well as a system for controlling the speed of movement of the head in the function of its load.

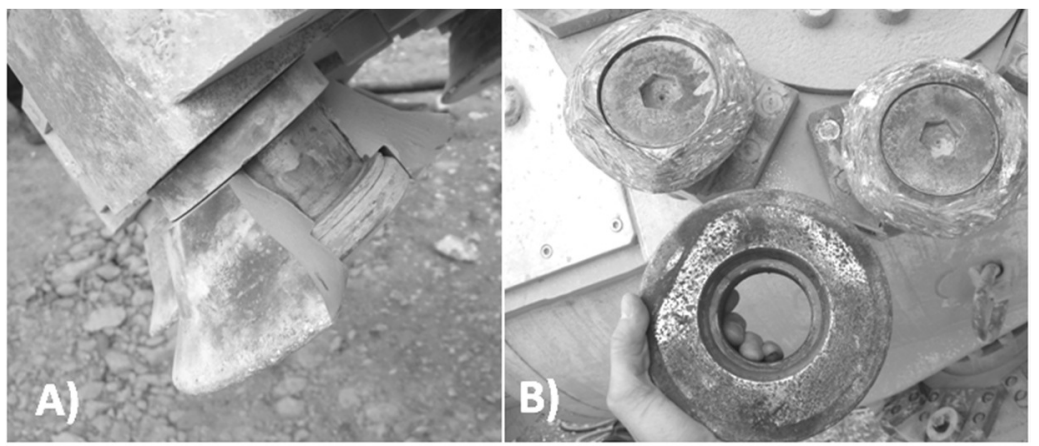

Fig. 12. A view of disk tool wear: A) made from steel type NZ3, B) made from ADI cast iron

It is proposed, before further industrial trials, to develop virtual models of disk tools and mining head and to conduct computer simulation tests. The results of research can allow to achieve satisfactory results at much lower costs (Tokarczyk, 2011).

\section{ACKNOWLEDGEMENTS}

The article was partially realized in the framework of the statutory activity of the Department of Mining, Dressing and Transport Machines AGH University of Science and Technology in the year 2018. 